\title{
Políticas da saúde e território: um debate em torno da realidade portuguesa à luz da visão de decisores políticos e instrumentos programáticos Health and territory policies: discussing the Portuguese context in light of programmatic instruments and decision-makers' perspectives
}

\section{Gonçalo Santinha}

Universidade de Aveiro. Departamento de Ciências Sociais. Políticas e do Território. Aveiro, Distrito de Aveiro, Portugal.

E-mail: g.santinhaळua.pt

\section{Correspondência}

Universidade de Aveiro. Campus de Santiago. Departamento de Ciências Sociais, Políticas e do Território. Aveiro, Portugal, CEP 3810-193.

\section{Resumo}

Neste artigo discute-se a importância que o território assume na formulação de políticas de saúde. Argumenta-se que o contexto territorial qualifica os processos de tomada de decisão política no que diz respeito à obtenção de ganhos em saúde e à relação equidade/eficiência, reforçando a necessidade de estreitar as sinergias entre as políticas de saúde e as de ordenamento do território. Na prática, porém, pouco se sabe sobre como e em que circunstâncias a dimensão territorial é levada em consideração na formulação de políticas. Centrado no caso português, neste artigo procura contribuir-se para esse debate por meio da auscultação das vozes dos atores que atuam na esfera da saúde. Foram, nesse contexto, entrevistados 23 decisores políticos, cuja partilha de perspetivas e experiências permitiu ter uma visão mais concreta, tanto da fileira do processo de decisão, como da natureza e dos mecanismos de articulação entre as principais instituições que são partes integrantes do sector da saúde. Essa organização metodológica foi complementada com uma análise dos instrumentos programáticos das políticas de saúde, que se, por um lado, influenciam os processos de tomada de decisão, por outro, são também fruto das prioridades definidas pelos decisores políticos. Conclui-se que ainda existe um modus operandi muito setorial e a-territorial que pressupõe um longo caminho ainda a percorrer de forma a conferir um sentido mais sustentado e integrado do ponto de vista da tomada de decisão política.

Palavras-chave: Políticas de Saúde; Território; Integração; Cooperação. 


\section{Abstract}

This study focuses on the role that the territory plays in health policy-making. It is argued that the territorial context enables the decision making processes concerning the improvement of health and the equity/efficiency trade-off, hence the importance of increasing collaboration between health policies and spatial planning. In reality, however, few things are known about how and in which circumstances the territory dimensions are taken into account in decision-making processes. Focused on the Portuguese case, this study debates this issue by listening to those who are or have been involved in health policy-making. A set of 23 interviews was conducted with actors who work in the health area, whose line of thought allowed the understanding of how health policies are developed and which institutional collaborations are established during the process. In addition, programmatic instruments of health policies were analysed to improve qualitative evidence about the spatial dimension of health policies. Findings show that there is still a long path ahead to integrate in a comprehensive manner the spatial dimension in health policy-making processes.

Keywords: Health Policies; Territory; Integration; Cooperation.

\section{Introdução}

O atual momento de crise económica e social tem conduzido diversos estados membros da União Europeia (UE) a um conjunto de reformas no seio das suas Administrações Públicas, na procura do modelo de organização mais eficiente para a prestação de serviços públicos. Embora a importância desses serviços - quer para a qualidade de vida dos cidadãos, quer para o desenvolvimento social e económico dos territórios - seja há muito reconhecida, o debate em torno do papel das políticas públicas na sua provisão tem ganhado uma maior visibilidade e centralidade nas agendas política, académica e mediática. Existem múltiplas razões que permitem explicar tal situação: as alterações políticas que, particularmente nas últimas duas décadas, visaram à liberalização dos mercados, à transição da ideia de utente de um serviço para a lógica do consumidor/ cliente ou mesmo à atual conjuntura económica e financeira.

Grande parte da discussão em torno dos serviços públicos, porém, tem sido efetuada de uma forma ampla e a-territorial. Segundo Pollitt:

[There is] a curious partial sightedness concerning the role of public services. [...] public services are frequently powerful placeshapers, and that their role in this regard has been largely ignored by most of the relevant academic literature. [...] Public services - health care, education, the police, social services, defence - they feature only rarely in the spatial planning literature [...] most of these services have their own spatial planning procedures and routines - hospitals are sited in relation to other hospitals and schools in relation to other schools rather than in relation to any more unified vision of the spatial disposition of the whole suite of public services and their integration with a wider plan for spatial development (2012, p. 33, 37-38).

Geddes et al. (2011, p. 35) acrescentam que "the lack of an integrated strategy across policy areas serves to perpetuate and possibly increase the lexisting] disadvantages [...] While separate working in 
silos continues, it will be harder to address these issues and tackle inequalities". Com efeito, alertando para a visão redutora que tradicionalmente se adota na discussão em torno desses serviços face ao seu potencial de transformação dos territórios e chamando a atenção para a visível ausência de articulação entre as diferentes áreas de intervenção, com as respetivas repercussões do ponto de vista da perpetuação das desigualdades existentes, esses autores confirmam a observação efetuada.

O caso da saúde constitui um bom exemplo da importância desse debate e cria as condições necessárias para uma reflexão sobre o modo como a dimensão territorial se encontra incluída nos processos de tomada de decisão. Diz Barros (2013) que a saúde surge regularmente no topo das principais preocupações expressas pelos cidadãos no âmbito de inquéritos sobre o que consideram essencial. No entanto, designadamente no caso português, eles manifestam uma insatisfação associada, em geral, ao sistema de saúde e aos cuidados prestados, em particular, no âmbito do Serviço Nacional de Saúde (SNS), e que resulta grosso modo de uma dificuldade sentida no acesso aos cuidados, seja pelos custos, seja pelo tempo de deslocação e de espera, seja ainda pela distribuição territorial dos serviços.

O sistema de saúde português tem por base um SNS, modelo de beveridge - princípio da cobertura universal, com financiamento obrigatório por via dos impostos, cuja gestão institucional é pública (Simões, 2009) -, a que tem acesso toda a população portuguesa por via de preceito constitucional. 0 sistema tem subjacente uma hierarquia funcional, cujo controlo, regulação e planeamento são exercidos pelo Ministério da Saúde e respetivas instituições da administração central. No entanto, a gestão é descentralizada pelas cinco Administrações Regionais de Saúde (ARS), cada qual respeitante a uma NUTS II, que, embora sob a alçada ao Ministério de Saúde, são responsáveis pela gestão estratégica da saúde da população, pela supervisão hospitalar, pela gestão dos cuidados de saúde primários e pela implementação dos objetivos traçados a nível nacional (para uma análise mais detalhada do sistema de saúde português, consultar obra de Barros, Machado e Simões, 2011). Apesar de o sistema ter essas carac- terísticas pré-definidas, por via também do preceito institucional, na prática tende a observar-se uma estrutura centralizada, já que a maioria dos poderes é exercida ao nível central (Oliveira; Pinto, 2005).

0 desagrado no que diz respeito à forma como as políticas de saúde estão a ser conduzidas no passado recente tem sido observado em diversos momentos. Por exemplo, em 2013, os presidentes das associações médicas e outras personalidades de Portugal e de três outros estados membros subscreveram uma carta aberta endereçada aos dirigentes políticos e às autoridades de saúde da Europa invocando uma rápida inversão das políticas de austeridade para "urgentemente evitar mais deterioração da saúde e dos serviços de saúde”. Argumentos como a visível diminuição do acesso a serviços de saúde apropriados, a existência de condições de trabalho deficientes para profissionais de saúde e a diminuição das verbas necessárias para desempenhos adequados por parte dos serviços públicos ao mesmo tempo que aumentam as necessidades em saúde na comunidade são aí apresentados como sinais de alerta para uma reflexão profunda sobre o rumo que as políticas de saúde devem tomar.

A essas preocupações associa-se outro conjunto de argumentos também amplamente difundido pelos meios de comunicação social e usados como justificação para algumas das orientações políticas em vigor: o sistema de saúde, tal como está, é insustentável e o Ministério da Saúde e, consequentemente, o SNS não se podem escusar de contribuir para uma maior contenção da despesa pública dada a situação de défice existente. Embora a essas razões acresçam outras mais relacionadas com a procura de uma melhoria da qualidade da prestação de cuidados, medidas como a concentração de serviços de saúde, o encerramento de determinadas unidades ou o aumento das taxas moderadoras, para citar alguns exemplos, têm gerado bastante controvérsia e incompreensão, não só às populações, mas também aos profissionais de saúde, no meio académico e no próprio círculo político.

Com efeito, pouco se conhece sobre quais os princípios e os critérios que estão na base de decisões políticas no campo da saúde e qual o papel que o território aqui ocupa. É verdade que há estudos que vão 
procurando apresentar um quadro histórico-político das principais reformas ocorridas em determinados períodos temporais, descrevendo, em alguns casos com bastante pormenor, os propósitos, os processos e os resultados alcançados por via das orientações traçadas. Exemplos podem ser encontrados em Campos (2008), Barros, Machado e Simões (2011), Campos e Simões (2011) e Fernandes e Barros (2012). Também é verdade que outros estudos se têm debruçado sobre as implicações de determinadas reformas no domínio da saúde junto de determinados grupos sociais, como os profissionais de saúde, por exemplo. Incluem-se aqui os trabalhos produzidos por Carvalho (2009) e Teixeira (2012) como referências nesse campo. No entanto, ao contrário dos trabalhos acima mencionados, que sistematizam numa única obra informação que se encontra dispersa ou que mostram a visão do próprio autor dos acontecimentos com base, em muitos casos, na sua própria experiência, a lógica adotada nessa segunda tipologia de estudos assenta predominantemente na recolha de informação à luz do discurso de vários intervenientes. Um traço comum que marca a generalidade dos estudos apontados, porém, é a parca análise do papel da dimensão territorial nas políticas da saúde.

Ora, é no domínio científico da geografia da saúde que mais se tem observado um crescente número de trabalhos que reconhecem que o território faz a diferença quando o alvo de estudo é a saúde. Em Portugal, os estudos desenvolvidos por Santana (2005, 2007, 2014) e Santinha (2013) inserem-se nesse campo concetual e analítico. Uma leitura desses trabalhos permite constatar que a formulação de políticas que contemplem a relação saúde/território de uma forma geral pode ser observada:

- Ao nível da natureza geográfica da acessibilidade aos cuidados de saúde.

- Em fatores de natureza mais ampla para além dos cuidados de saúde per se, tais como o impacto social, económico e político que os serviços de saúde provocam ao nível local ou mesmo a aposta em comportamentos e estilos de vida (ótica da promoção da saúde e prevenção da doença).
- Na importância que a saúde apresenta enquanto atividade exportadora e meio gerador de emprego e alavancador de desenvolvimento social, económico territorial (com ligações a outras atividades, destacando, como exemplo, o turismo médico ou de saúde e bem-estar).

Contudo, em estudos desse âmbito da geografia da saúde tende a estar ausente a análise da conceção política das orientações reformadoras e a perceção sociológica dos princípios e critérios subjacentes a essas mesmas orientações. Por que, como e em que circunstâncias a dimensão territorial é tida em conta na formulação de políticas de saúde? Quais os critérios usados? Será essa articulação saúde/ território considerada de forma pontual ou sistemática? E do ponto de vista institucional, como é efetuada a articulação entre agentes e instrumentos de saúde com os de base territorial de forma a formular e implementar políticas integradoras? É precisamente sobre essas questões que este texto se debruça, procurando contribuir para esse debate no campo das políticas de saúde. A organização do resto do artigo contempla quatro secções. Na próxima secção explicitam-se as opções metodológicas que presidiram à prossecução dos objetivos delineados na pesquisa efetuada. Nos dois pontos subsequentes, apresentam-se e discutem-se os resultados alcançados. Por fim, na última secção, efetuam-se alguns comentários finais sobre a relação cuidados de saúde/território à luz dos resultados obtidos no trabalho empírico.

\section{Material e método}

Por se tratar de um tópico de interesse cujo conhecimento ainda se encontra numa fase embrionária e que constitui a preocupação central em perceber os processos de tomada de decisão - no fundo, como refere Yin (1994), centrando a investigação no como e no porquê -, o estudo revela-se de natureza exploratória e não afirmativa, procurando, por essa via, gerar conhecimento e não testar o conhecimento, identificando fatores relevantes e propondo hipóteses para estudos subsequentes (Marshall; Ros- 
sman, 1999). Opta-se, assim, por uma metodologia de abordagem essencialmente qualitativa, baseada na realização de entrevistas conduzidas presencialmente a um conjunto de atores-chave, para se compreender com profundidade o fenómeno social em discussão. A utilização das entrevistas nesse âmbito permite uma forte interação dos intervenientes (investigador e entrevistado) sobre o processo e o contexto em que as experiências em discussão ocorrem, possibilitando compreender a realidade à luz do olhar dos atores. Essa preocupação metodológica, condicionada pelas características específicas da pesquisa, motivou a realização de entrevistas semiestruturadas a um conjunto de atores-chave da esfera da decisão pública no domínio da saúde que pudessem, por meio de um discurso direto, expor os seus argumentos e experiências sobre se a dimensão territorial é considerada no processo de formulação de políticas de saúde (em geral) e dos cuidados de saúde (em particular) no contexto português e, em caso afirmativo, como isso acontece. Mais concretamente, a condução deste estudo teve por base três questões de investigação operacionais:

- Como são formuladas as políticas de saúde (em geral) e dos cuidados de saúde (em particular)?

- Em que medida os princípios e critérios utilizados na formulação de políticas de cuidados de saúde (níveis de decisão nacional e regional) consideram a dimensão territorial?

- Qual a sensibilidade dos decisores face à relação cuidados de saúde/território nos processos de tomada de decisão?

Para se compreender e interpretar a realidade dos processos de tomada de decisão em saúde e a sua relação com a dimensão territorial, assegurou-se a participação, em primeiro lugar, de personalidades que têm ou tiveram responsabilidades governamentais na formulação de políticas de saúde, isto é, indivíduos que tenham exercido cargos governamentais no Ministério da Saúde, tendo presente o garante da representatividade político-partidária. Alargou-se, ainda assim, o campo representacional, garantindo o envolvimento de representantes de outras entidades com capacidade decisória ao nível das políticas de saúde. Incluem-se, aqui, responsáveis de entidades direta ou indiretamente ligadas à Administração Central e Regional que, pelo seu cargo e a sua experiência, poderiam alargar o leque de informação e de detalhe sobre os processos de tomada de decisão em saúde. Embora a escolha dos respetivos atores tenha implicado uma análise prévia - quer dos diferentes governos institucionais do passado recente do contexto português, quer das instituições que deveriam ser alvo de auscultação - resultou igualmente de indicações que os primeiros entrevistados foram dando, uma abordagem que segue, de certa forma, a lógica da bola de neve (snowball sampling, segundo Yin, 1994), o que, por sua vez, facilita o contacto posterior com esses atores a entrevistar. O público-alvo compreendeu, então, os seguintes grupos de personalidades:

- Indivíduos que exerçam ou tenham exercido cargos governamentais no Ministério da Saúde (Ministros e/ou Secretários de Estado), tendo presente o garante da representatividade político-partidária.

- Representantes de entidades da Administração Central, designadamente a Direção Geral da Saúde (DGS), o Instituto Nacional de Emergência Médica (INEM), a Administração Central do Sistema de Saúde (ACSS), o Instituto Nacional de Saúde Doutor Ricardo Jorge (INSA) e o Alto Comissariado (entretanto extinto).

- Representantes de entidades independentes da Administração Central, nomeadamente a Entidade Reguladora da Saúde (ERS) e as Unidades de Missão para os Cuidados de Saúde Primários (MCSP) e para os Cuidados Continuados Integrados (MCCI).

- Representantes das Administrações Regionais de Saúde (ARS).

Foram 23 entrevistas realizadas em 2012 e 2013. No seguimento da realização das entrevistas, gravadas em sistema áudio, procedeu-se à sistematização e análise do discurso dos atores no sentido de perceber a sua posição diante dos objetivos delineados.

Essa organização metodológica foi complementada com uma análise de conteúdo documental, 
designadamente de instrumentos programáticos das políticas de saúde. Instrumentos que se, por um lado, influenciam processos de tomada de decisão, por outro, são também fruto das prioridades definidas pelos decisores políticos. Essa abordagem, que na sua natureza segue a mesma linha de pensamento das entrevistas (Stake, 1995), mas acrescenta outras interrogações, visou aferir em que medida a dimensão territorial é objeto de preocupação dos principais instrumentos de política de saúde. Os instrumentos programáticos analisados foram selecionados como aqueles que, segundo os entrevistados, detêm maior importância na formulação e implementação de políticas de saúde, a saber:

- Programa do XIX Governo Constitucional e Grandes Opções do Plano 2012-2015, como sendo os principais instrumentos de natureza estratégica governativa.

- Memorando de Entendimento sobre as Condicionalidades de Política Económica, enquanto instrumento condicionador da linha estratégica da saúde em Portugal;

- Plano Nacional de Saúde (PNS 2012-2016), enquanto instrumento estratégico e programático por excelência para a saúde em nível nacional.

- Redes de Referenciação Hospitalar, enquanto instrumentos para o planeamento e organização da resposta por parte dos prestadores de cuidados de saúde.

- Carta Hospitalar (ainda em fase de proposta), enquanto instrumento útil para conhecer a realidade nacional no que respeita à organização e valências dos prestadores de cuidados de saúde.

- Planos Regionais de Saúde (disponíveis somente para quatro regiões NUTS II), enquanto instrumentos estratégicos para as intervenções políticas e técnicas a nível regional.

\section{A perspetiva dos decisores políticos}

O primeiro ponto consistiu em tentar compreender quais as principais preocupações que estão na génese dos processos de tomada de decisão. A res- posta dos entrevistados centrou-se, essencialmente, na equidade e na eficiência enquanto princípios que devem nortear a formulação de políticas de saúde (em geral) e dos cuidados de saúde (em particular). Nas suas palavras, eficiência porque os recursos são finitos, principalmente no contexto atual, pelo que deve haver uma utilização racional dos mesmos, e equidade na medida em que os cidadãos devem ter o direito à saúde de acordo com as suas necessidades (independentemente da sua capacidade de pagar, da condição de trabalho ou do nível social). Observou-se, nessa primeira reação, um quase total alheamento do domínio territorial no seu discurso. Uma postura que parece indiciar que, de uma forma geral, os decisores de políticas de saúde não articulam de forma natural e espontânea a área da saúde com a dimensão territorial ao nível do pensamento estratégico.

Quando confrontados com questões mais concretas do ponto de vista das noções de equidade e eficiência, porém, a argumentação apresentada evidenciou que as prioridades estão centradas, por um lado, na lógica da proximidade aos serviços de saúde (no que diz respeito aos cuidados de saúde primários e cuidados continuados) e, por outro, na ideia da concentração de serviços por motivos de procura de ganhos em economias de escala, de eficiência e de qualidade, em relação essencialmente aos cuidados hospitalares. Pela atual conjuntura de restrição financeira e porque os cuidados hospitalares absorvem uma fração considerável dos recursos despendidos pelo SNS, as principais preocupações avançadas pelos entrevistados centraram-se na necessidade de se reorganizar os serviços de saúde prestados, devido à excessiva oferta de cuidados hospitalares, a sua ineficiente organização interna, a não continuidade das reformas dos cuidados de saúde primários e à parca articulação existente entre os diferentes tipos de cuidados.

O segundo ponto consistiu em percecionar como são formuladas e implementadas as orientações de política no domínio da saúde (em geral) e dos cuidados de saúde (em particular). Importa, desde logo, realçar o facto de que para os entrevistados as decisões devem ser de natureza política, independentemente do tipo de métodos que se utilizem. Isto 
é, os resultados obtidos por meio de um determinado método de apoio à decisão (por intermédio de uma Análise Custo-Benefício ou de Análise Multicritério, ou do desenvolvimento de técnicas de participação dos principais agentes ou dos cidadãos em geral) podem indicar um determinado caminho, mas a decisão final do político pode acabar por ir noutra direção. No entanto, e apesar de quase metade dos entrevistados não utilizar um procedimento em concreto nos processos de tomada de decisão, na generalidade reconhecem que as decisões devem basear-se em informação (componente técnica) e ter em consideração o diálogo e o envolvimento das partes interessadas. Por outro lado, o facto de não associarem os métodos de suporte à decisão a objetivos de política e escalas de atuação concretas não permite aferir se o peso relativo de cada uma dessas componentes varia com as escalas e com a dimensão e complexidade das questões em causa. Esse fator sugere algum alheamento por parte dos decisores diante das vantagens decorrentes do uso de métodos de suporte à decisão e sobre quando e como se devem utilizar.

O terceiro ponto de análise introduziu com maior profundidade a dimensão territorial na discussão, ou seja, procurou aferir se e como o território é considerado nas políticas de saúde e se, consequentemente, transporta uma racionalidade supletiva para os processos de tomada de decisão. Um traço que marca o discurso da generalidade dos entrevistados é o facto de a dimensão territorial na saúde ser entendida enquanto acesso geográfico aos cuidados e, consequentemente, parte integrante do princípio de equidade. Desse modo, as principais preocupações incidem na melhoria da prestação de cuidados de proximidade, na reorganização dos cuidados hospitalares (e resultante diminuição dos seus custos) e na procura de uma maior articulação entre os diferentes tipos de prestação de cuidados. Critérios do lado da oferta (como tirar partido de economias de escala e considerar a importância da casuística) e da procura (como atender aos custos de deslocação e de oportunidade) estão patentes enquanto fatores a considerar na tomada de decisão, mas estando sempre presente na argumentação a necessidade de se efetuar uma discriminação positiva das áreas mais remotas e de determinados grupos sociais (designadamente os mais idosos) para promover uma maior equidade de acesso aos cuidados de saúde e justificar, ou a presença de determinados serviços de saúde em determinados locais com menor densidade demográfica, ou preferencialmente a procura de soluções alternativas de acesso. A questão que fica sem uma resposta precisa é como determinar quando e em que circunstâncias atuar numa ótica de discriminação positiva. De facto, quando confrontados com esse quesito, a explicação incidiu, de uma forma geral, na necessidade de se juntar o bom senso político a critérios técnicos geográficos e sociais, como distâncias ou tempos de deslocação, dispersão populacional e nível de rendimento, sem contudo se avançar com explicações ou critérios mais detalhados.

0 facto de a maioria dos entrevistados compreender e precisar a problemática em estudo em termos teóricos, articulando as ideias de equidade e eficiência com as questões territoriais ao nível da formulação de políticas, ainda que praticamente só quando confrontados e impelidos a refletir especificamente sobre a relação saúde/território, indicia que, de uma forma global, decisores e ex-decisores de políticas de saúde são sensíveis à articulação desses domínios de saber. No entanto, a discrepância de opiniões e o reduzido grau de profundidade observado no discurso quanto à relação políticas/escalas de intervenção/instituições/instrumentos de política a utilizar indiciam uma maior dificuldade em traduzir em ações práticas objetivos de política que congreguem tais domínios de saber e um menor envolvimento desses agentes nas estratégias discutidas no nível da implementação.

Para uma melhor perceção da importância da dimensão territorial para a formulação de políticas de saúde, foram discutidos outros dois domínios de análise que, no seu conjunto, permitem não só considerar impactos sociais que vão para além dos cuidados de saúde stricto sensu, mas também olhar para o território enquanto oportunidade e fator alavancador de desenvolvimento. Inclui-se nessa visão mais ampla, por um lado, a consciencialização do impacto social, económico e político que os serviços de saúde provocam ao nível local e 
da importância dos comportamentos e estilos de vida numa ótica da promoção da saúde e prevenção da doença (o que incute uma potencial articulação entre a saúde e outras áreas de intervenção) e, por outro, a perceção da importância da saúde enquanto atividade exportadora para o desenvolvimento da economia e dos territórios. Contudo, embora seja opinião generalizada que esses domínios de atuação devem ser levados em consideração na formulação de políticas de saúde e complementar a visão típica centrada nos cuidados de saúde per se, aqui os entrevistados adotaram um discurso mais cauteloso e ambíguo, apresentando respostas com um nível de profundidade inferior, o que de certa forma sugere que são áreas para as quais os entrevistados apresentam um menor envolvimento e sensibilidade.

De acordo com os entrevistados, a consideração desses domínios complementares pode acrescentar valor aos processos de tomada de decisão em saúde se os seguintes objetivos de política forem levados em consideração:

Promover a saúde das comunidades, incrementando a literacia em saúde e melhorando os comportamentos e estilos de vida, o que implica considerar a saúde de uma forma mais abrangente e articulada com outras áreas de intervenção;

Diligenciar uma melhor organização dos serviços de saúde, articulando a oferta de cuidados dos aglomerados com maior população com as necessidades das populações dos locais com menor densidade ou procurando soluções alternativas de acesso, o que traduz uma compreensão acrescida dos impactos das decisões políticas (que podem variar de acordo com os contextos territoriais);

Delinear uma estratégia para o turismo de saúde (médico), desenvolvendo estudos sobre a potencial procura e a oferta existente, abrindo espaços de discussão, criando nichos de mercado (competir pela diferenciação), definindo novas formas organizacionais por parte dos cuidados hospitalares e valorizando infraestruturas existentes, promovendo a articulação entre as instituições de saúde e as do setor do turismo, o que implica apostar na saúde também numa ótica biunívoca de prestação de cuidados/desenvolvimento da economia.
Se é certo que a compreensão da importância desses dois domínios analíticos adicionais reforça a necessidade de articular políticas tipicamente setoriais (saúde com ordenamento do território e turismo, por exemplo), não é menos verdade que tal implica perceber com maior profundidade como as relações institucionais se processam, isto é, quais os mecanismos de governança. A esse nível importa refletir particularmente sobre como os decisores e ex-decisores de políticas da saúde consideram a articulação dessa área com as políticas de base territorial. Um traço que marca transversalmente o início das entrevistas é o pouco entendimento sobre a (potencial) relação entre as políticas de saúde e as do ordenamento do território. De facto, é curiosa a reação de diversos entrevistados, quer no momento da marcação dos encontros, quer durante a sua fase inicial, em que se discute o propósito da pesquisa, mencionando que pouco poderiam dizer e acrescentar sobre essa questão e que a relação entre as duas áreas é praticamente inexistente.

Quando instigados a refletirem e comentarem sobre as relações interinstitucionais existentes no âmbito da saúde, os entrevistados unanimemente sublinharam a importância de formular e implementar políticas públicas assentes num contexto de diálogo e cooperação entre as diversas áreas setoriais de intervenção pública, independentemente da escala de atuação (nacional, regional ou local). Contudo, a importância da articulação com o campo do ordenamento do território estava, não raro, ausente das suas observações, preferindo incidir mais com áreas como a Educação, a Economia ou o Ambiente. É verdade que independentemente da área de articulação, de acordo com o seu conhecimento e experiência, a realidade mostra-se bastante distante desse desiderato (importância da articulação interinstitucional). No entanto, essa questão é ainda mais premente no que diz respeito à relação com a área do ordenamento do território. De facto, as interações institucionais têm sido inexistentes ou simplesmente baseadas em cooperações pontuais, particularmente por motivos associados aos quadros de programação financeira, em muito por três razões: pela falta de uma cultura organizacional, por uma incompreensão mútua de como encetar 
processos mais colaborativos ou pela forma como o ordenamento do território é considerado (negativamente) pelos atores do lado da saúde.

Diante desse panorama, não é de estranhar que, para os entrevistados, os objetivos de política passem essencialmente por criar soluções organizacionais adequadas e uma prática cultural sistemática (que em muito passa pela capacidade de liderança) para promover a coordenação conjunta de políticas de forma articulada e visível para a população nas diferentes escalas de atuação. A aposta na ideia de saúde em todas as políticas surge aqui como uma forma de conseguir induzir uma maior articulação interinstitucional, incorporando a saúde e o bem-estar como componentes centrais no desenvolvimento de outros domínios setoriais.

\section{As orientações programáticas}

A leitura transversal dos instrumentos analisados sugere que as estratégias aí definidas para a saúde consideram a dimensão territorial, ainda que uma vez só implicitamente e outras com pouco grau de detalhe. Em primeiro lugar, denotam uma preocupação com a cobertura geográfica e a acessibilidade aos cuidados de saúde, seja numa ótica de garantir uma difusão dos cuidados de saúde primários para proporcionar uma maior proximidade às populações, seja com o intuito de reforçar a concentração de serviços hospitalares ou inclusive com o propósito de reorganizar (numa lógica sinergética) os cuidados primários, hospitalares e continuados. Em segundo lugar, reforçam a importância das estratégias com vista à promoção da saúde e da influência do meio ambiente na saúde das populações, o que implica ter em consideração aspetos como a educação, o ambiente e o espaço urbano, entre outros, na definição de estratégias da saúde. Em terceiro lugar, valorizam as estruturas institucionais multiníveis (ideia de coordenação vertical), assumindo a escala regional um papel de relevo para a definição das suas opções estratégicas adaptadas ao respetivo contexto territorial, e estimulam a participação de outros agentes nos processos de tomada de decisão em saúde (ideia de coordenação horizontal), o que significa reconhecer que a saúde não deve estar fechada em si mesma do ponto de vista dos mecanismos de governança.

Ao invés, a tradução espacial, quer das análises que apresentam, quer do ponto de vista das orientações estratégicas delineadas, útil para verificar as disparidades geográficas existentes em vários indicadores de saúde e aferir a acessibilidade aos serviços de saúde, é muito pouco explorada: nos três instrumentos em que o mapeamento ocorre, só na proposta da Carta Hospitalar é que se verifica um maior grau de detalhe e somente ao nível da localização geográfica dos hospitais.

Trata-se, portanto, de quatro vertentes analíticas - cobertura e acessibilidade geográfica, promoção da saúde, governança (coordenação horizontal e vertical) e mapeamento espacial (serviços de saúde e perfil da população) - em que é possível observar, ainda que com níveis de detalhe diferentes, a dimensão territorial imbuída nas orientações estratégicas dos instrumentos em causa.

Contudo, importa também refletir sobre o que fica ausente desses instrumentos do ponto de vista da relação saúde/território. Em primeiro lugar, embora haja indicações gerais para a necessidade de estimular uma articulação intersectorial, advogando-se inclusive a ideia de saúde em todas as políticas, a componente do ordenamento do território é, na maioria das ocasiões, parcamente mencionada, recaindo a preferência relacional com o sector da educação. Mesmo quando se incide na ideia de políticas saudáveis, reconhecendo-se o impacto que o meio ambiente pode produzir na saúde das populações, as referências incidem predominantemente no sector ambiental. Por outro lado, em nenhum dos casos é feita qualquer referência a orientações que estejam a ser desenvolvidas em nível de ordenamento do território de forma a articular o planeamento da saúde com as opções de desenvolvimento de base territorial e, consequentemente, a responder a desafios mais vastos que a sociedade contemporânea coloca, em que se alia o combate às assimetrias sociais, económicas e territoriais à valorização das especificidades locais e respetivos recursos endógenos.

A essas observações sobre o conteúdo dos instrumentos analisados convém acrescentar outra: 
a importância que eles podem assumir ao nível do processo do seu desenho. Por outras palavras, esses instrumentos programáticos podem (e devem) constituir processos coletivos de construção social, de criação de uma visão e aprendizagem conjunta - nesse contexto, refere-se à importância de um instrumento como o Plano Nacional de Saúde. Com efeito, a sua elaboração constituiu um processo contínuo e evolutivo, que resultou também da aprendizagem da elaboração do plano anterior (2004-2010), e acompanhado pela produção de vários documentos sectoriais (com maior ou menor influência posteriormente no próprio plano), valorizando a vertente estratégica e procurando constituir-se enquanto quadro de referência para a política de saúde em Portugal e veículo de articulação entre diferentes domínios políticos e escalas territoriais, de forma a garantir uma maior coordenação de políticas e intervenções. E pensar o planeamento da saúde de forma a articular diferentes escalas e áreas de intervenção pressupõe considerar que a dimensão territorial ganha preponderância e é parte de um sistema de governança com diferentes níveis de coordenação vertical e horizontal.

A natureza dos Planos Regionais de Saúde confere-lhes a mesma importância que o Plano Nacional de Saúde ao nível do processo. É certo que ainda poucos estão publicados e que há alguma discrepância entre os planos regionais do ponto de vista do detalhe e alcance das linhas de orientação definidas, o que em parte é demonstrativo da falta de orientações nesse sentido das entidades governativas e da Administração Central. Também é verdade que a área do ordenamento do território não está explicitamente vincada nesses planos, revelando pouca consciência/ sensibilidade sobre as potencialidades que podem advir da relação saúde/território. Mas, do ponto de vista processual, a sua análise documental evidencia que estão previstos mecanismos de disseminação dos planos junto da população e que houve uma preocupação geral em envolver diversos agentes durante seu próprio período de elaboração. Tal significa que há um cuidado em não só dar a conhecer os resultados e as estratégias desses instrumentos, mas simultaneamente mobilizar e proporcionar meios para participar na sua construção.

\section{Considerações finais}

A pesquisa efetuada procurou perceber se e, em caso afirmativo, como a dimensão territorial é levada em consideração nos processos de tomada de decisão em saúde. Trata-se de um tópico ainda pouco explorado cientificamente, mas cuja importância é capital para se apostar numa maior integração de políticas públicas tradicionalmente concebidas de forma segmentada. De forma a contribuir para esse debate no campo das políticas públicas e da geografia da saúde, a pesquisa centrou-se no caso português, um país tradicionalmente retratado em diversos estudos comparados ao nível político-territorial como sendo de organização do tipo "passiva”, típica dos países europeus mediterrânicos (por exemplo, Rauhut et al, 2013): com uma fraca organização territorial de serviços públicos e uma tendência centralizadora da administração e do planeamento. Com o recurso a uma abordagem metodológica que permitisse beneficiar da experiência e do conhecimento dos principais atores da política da saúde nacional, realizaram-se mais de duas dezenas de entrevistas semiestruturadas a agentes da esfera da decisão pública nesse domínio. A compreensão do fenómeno em causa foi, posteriormente, alicerçada de forma complementar numa análise de conteúdo documental dos instrumentos programáticos das políticas de saúde.

Em termos de considerações finais, importa começar por referir a dificuldade encontrada na realização desta pesquisa, em virtude do distanciamento assinalável que a temática do ordenamento do território apresenta no discurso da maioria dos atores entrevistados, o que indicia desde logo uma reduzida articulação entre a área da saúde e a componente territorial, não só do ponto de vista do pensamento estratégico, mas sobretudo ao nível operacional. É certo que no desenrolar das entrevistas a maioria dos auscultados acabou por evidenciar uma compreensão do fenómeno em estudo em termos teóricos. No entanto, a reduzida capacidade demonstrada sobre como traduzir em ações práticas objetivos de política que congreguem tais domínios de saber ajuda a explicar a (pouca) cooperação verificada entre as diversas instituições, bem como a 
importância atribuída à capacidade de liderança, fator fundamental, na ótica dos entrevistados, para a obtenção de bons resultados. É, de facto, um traço comum que marca a posição dos decisores de políticas de saúde, sublinhando que, independentemente da maior ou menor aptidão de articular a saúde com a dimensão territorial em nível da formulação de políticas, a capacidade de as traduzir em ações práticas depende de quem lidera os processos e da sua capacidade de mobilizar as estruturas locais. Uma visão que vai ao encontro do que Beer e Clower (2014, p. 5) indicam como "charismatic individuals who are seen to be an important lightning rod for bringing about change and positive development".

O segundo comentário diz respeito à articulação que necessariamente deve haver dos três domínios analíticos aqui mencionados e discutidos com os entrevistados - natureza geográfica da acessibilidade aos cuidados de saúde, fatores de natureza mais ampla para além dos cuidados de saúde per se, importância que a saúde apresenta enquanto atividade alavancadora de desenvolvimento social, económico e territorial - de forma a integrar a dimensão territorial na formulação de políticas de saúde. E aqui importa realçar que foi opinião generalizada que uma visão capaz de articular esses domínios tornaria os processos de tomada de decisão mais ponderados, justos e eficientes (não só na perspetiva da saúde, mas numa ótica mais global). Porém, também ficou espelhado que a adoção dessa perspetiva conjunta não se afigura simples. O facto de se tratar de uma temática (relação cuidados de saúde/ordenamento do território) que ainda se encontra por debater, refletir e explorar e para a qual os atores não estão completamente sensibilizados, significa que a mudança da praxis enraizada muito dificilmente surgirá de forma espontânea, implicando, pelo contrário, um processo longo de capacitação das lideranças e dos profissionais.

0 terceiro comentário diz respeito à articulação institucional observada entre as áreas da saúde e do ordenamento do território: é inexistente ou simplesmente baseada em torno de questões pontuais, particularmente por motivos associados aos quadros de programação financeira. Foram essencialmente três os motivos apontados: falta de uma cultura organizacional, incompreensão mútua de como encetar processos mais colaborativos e, ainda, forma depreciativa como o ordenamento do território é considerado pelos decisores políticos da saúde. Esse modus operandi sugere, à partida, a necessidade de se criar uma cultura mais forte de cooperação intersectorial por meio do desenho de soluções organizacionais adequadas para promover a coordenação conjunta de políticas. A aposta na ideia de saúde em todas as políticas pode, com efeito, constituir aqui uma oportunidade para induzir essa maior articulação interinstitucional, incorporando a saúde e o bem-estar como componentes centrais no desenvolvimento de outros domínios setoriais.

Essa perspetiva pressupõe também que os instrumentos programáticos de política sejam imbuídos de uma visão multissectorial, ocupando a articulação do domínio da saúde com o ordenamento do território um lugar visível. A leitura transversal dos instrumentos-chave apontados pelos decisores políticos sugere que as estratégias aí definidas para a saúde, embora variando em grau de detalhe, consideram a dimensão territorial: há uma preocupação, ainda que por vezes só implícita, com a cobertura geográfica e a acessibilidade aos cuidados de saúde, reforçam a importância da promoção da saúde e da influência do meio ambiente na saúde das populações. Por outro lado, e embora haja indicações gerais para a necessidade de estimular uma articulação intersectorial, com o sublinhar da já mencionada ideia de saúde em todas as políticas, a menção ao ordenamento do território é quase inexistente. Por exemplo, em nenhum caso são referidas as orientações delineadas pelos instrumentos de ordenamento do território, o que permitiria articular o planeamento da saúde com as opções de desenvolvimento de base territorial e, consequentemente, conjugar o combate às assimetrias sociais, económicas e territoriais com a valorização das especificidades locais e respetivos recursos endógenos.

Com a clara perceção do profundo subaproveitamento que os principais instrumentos programáticos fazem da potencial relação saúde/ordenamento do território, foi defendido pelos entrevistados que o processo de elaboração de determinados instrumentos poderia instigar a participação de vários 
atores a pensar a saúde nos moldes em discussão. A esse propósito, o Plano Nacional de Saúde e os Planos Regionais de Saúde são apontados como aqueles que apresentam maior potencial. Já no que diz respeito ao eventual papel que os planos de ordenamento do território possam adquirir a esse nível, a reação da maioria dos atores foi perentoriamente desfavorável: apesar do potencial que se lhes reconhece, a reduzida capacidade operacional dos planos de ordenamento à escala regional e a rigidez e pouca visão estratégica que, na prática, e segundo os entrevistados, pautam os planos à escala local, sugerem que pensar nesses instrumentos como fatores indutores de uma maior colaboração entre as duas áreas de intervenção não é, atualmente, viável. A menção a esses instrumentos acrescenta à discussão a importância que as escalas regional e local assumem a esse propósito. De facto, na ótica dos entrevistados, a escala regional representa o nível ideal para promover a articulação interinstitucional e intersectorial, na medida em que não só a forma de tomar decisões varia com os contextos territoriais, como também, do ponto de vista institucional, é a essa escala que se procuram sistematizar as orientações que emanam do nível nacional. Já no que diz respeito à escala local, esta é a que apresenta apesar de tudo maior experiência ao nível da articulação institucional e intersectorial e, também por isso, é o palco por excelência para a promoção de uma maior cooperação com as autarquias e as comunidades, designadamente no que diz respeito a questões relacionadas à promoção da saúde.

Por fim, importa referir que os resultados alcançados confirmam a posição político-territorial tradicionalmente atribuída a Portugal em nível da organização, planeamento e prestação de serviços públicos, desta feita para o caso específico dos serviços de saúde, e mostram que, por um lado, subsiste uma visão que coloca no centro das decisões públicas critérios sectoriais concebidos de uma forma redutora e fragmentada no que se refere à dimensão territorial e, por outro, o debate sobre as potencialidades, a conceção e a operacionalização de políticas de saúde, levando em consideração a dimensão territorial, encontra-se em grande medida por fazer. Mas esses resultados lançam também pistas para uma agenda de investigação futura, na qual se deve contemplar uma análise mais vasta de outras realidades para se tirarem ilações sobre como atuar no sentido de promover uma maior coordenação e cooperação entre os domínios da saúde e do ordenamento.

\section{Referências}

BARROS, P. Pela sua saúde. Lisboa: FFMS, 2013

BARROS, P.; MACHADO, S.; SIMÕES, J. Portugal: Health system review. Health Systems in

Transition, Copenhagen, v. 13, n. 4, p. 1-156, 2011.

BEER, A.; CLOWER, T. Mobilizing leadership in cities and regions. Regional Studies, Regional

Science, Seaford, v. 1, n. 1, p. 5-20, 2014.

CAMPOS, A. Reformas da saúde: o fio condutor. Coimbra: Almedina, 2008.

CAMPOS, A.; SIMÕES, J. (Org.). O percurso da saúde: Portugal na Europa. Coimbra: Almedina, 2011.

CARVALHO, T. Nova gestão pública e reformas da saúde: 0 profissionalismo numa encruzilhada. Lisboa: Sílabo, 2009.

FERNANDES, J.; BARROS, P. Um ano depois da Troika na Política de Saúde. Cascais: Princípia, 2012.

GEDDES, I. et al. The Marmot Review: implications for Spatial Planning. London: The Marmot Review Team, NICE, 2011.

MARSHALL, C.; ROSSMAN, G. Designing qualitative research. Thousand Oaks, California: Sage Publications, 1999.

OLIVEIRA, M; PINTO, C. Health Care Reform in Portugal: an evaluation of the NHS Experience. Health Economics, Chichester, n. 14, p. S2O3-S22O, 2005 .

POLLITT, C. New perspectives on public services: place and technology. Oxford: Oxford University Press, 2012.

RAUHUT, D. et al. (Org.). SeGI: Indicators and Perspectives for Services of General Interest in Territorial Cohesion and Development - Final 
report. Luxembourg: ESPON, 2013. Disponível em: <http://www.espon.eu/main/Menu_Projects/ Menu_AppliedResearch/SeGI.html >. Acesso em: 4 maio 2015 .

SANTANA, P. Introdução à Geografia da Saúde: território, saúde e bem-estar. Coimbra: Imprensa da Universidade de Coimbra, 2014.

SANTANA, P. Geografias da saúde e do desenvolvimento: evolução e tendências em Portugal. Coimbra: Almedina, 2005.

SANTANA, P.; MACHADO, M. (Org.). A cidade e a saúde. Coimbra: Almedina, 2007.

SANTINHA, G. Cuidados de Saúde e Território: um debate em torno de uma abordagem integrada.
Saúde e Sociedade, São Paulo, v. 22, n. 3, p. 815829, 2013.

SIMÕES, J. Tendências internacionais nas políticas públicas de saúde. Janus, Lisboa, n. 2, p. 1-7, 2009.

STAKE, R. The art of case study research. Thousand Oaks: Sage Publications, 1995.

TEIXEIRA, L. A reforma do centro de saúde: percursos e discursos. Lisboa: Mundos Sociais, 2012.

YIN, R. Case study research: Design and methods. Thousand Oaks: Sage, 1994. 